\title{
OPTIMIZACIÓN Y APROVECHAMIENTO DEL RESIDUO (EXUDADO DEL MUCÍLAGO) DE LA ALMENDRA FRESCA DEL CACAO (THEOBROMA CACAO L.) CCN51 EN LA ELABORACIÓN DE VINAGRE
}
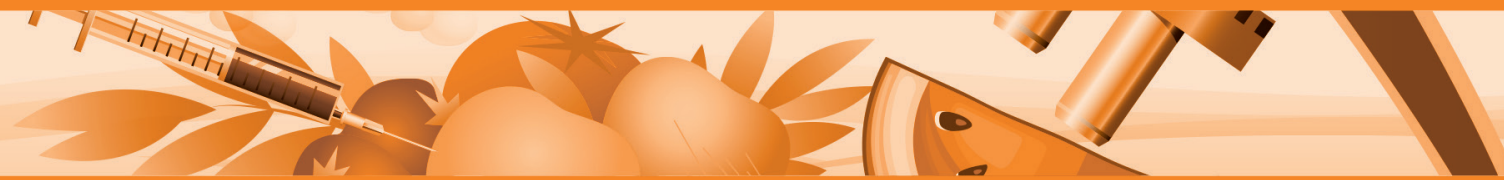

Autores:

Sebastián Villagómez García ${ }^{1}$

Fanny Argüello Moreta' 


\section{Resumen}

El presente trabajo investigó la factibilidad de obtener un producto fermentado como es el vinagre, resultado de un proceso piloto controlado, que consistió en diseñar y elaborar un acetificador piloto a pequeña escala basado en el acetificador Frings y, partiendo del vino del mucílago del cacao CCN51 como sustrato a través de una fermentación sumergida y utilizando como inóculo el cultivo "madre del vinagre" obtener vinagre de acuerdo con la norma INEN 2296 "vinagre requisitos". El vinagre se obtuvo mediante dos procesos microbianos separados: una fermentación alcohólica de los azúcares naturales presentes en el exudado del mucílago de cacao y una fermentación oxidativa del alcohol obtenido. Se realizó la caracterización química del sustrato, estableciendo las condiciones óptimas para una fermentación acética. Se utilizó un diseño completamente al azar considerando el efecto de la exposición al O2 en 3 niveles (T1=24, T2=18, T3=12 horas/día) de tiempos de aireación diferentes, cada tratamiento con dos repeticiones utilizando como unidad de volumen de oxigenación constante 0.5 vvm (volumen de aire por unidad de volumen de medio por minuto), evaluando el efecto sobre la producción de ácido acético (g/L) así como las características fisicoquímicas y sensoriales del vinagre final. Los datos fueron analizados estadísticamente, determinándose que el T1 fue el óptimo obtenido, habiendo alcanzando la mayor producción de ácido acético $4.05 \mathrm{~g} / \mathrm{L}$, como resultado de una mayor concentración de oxígeno disuelto en la fermentación, cumpliendo además con las especificaciones de la norma INEN 2296. Además T1 obtuvo un mayor puntaje (3.94/5) en cuanto a la aceptabilidad global en la evaluación sensorial por atributos respecto a T2 y T3. Se concluyó que la fermentación acética dada al vino del mucílago del cacao CCN51 con un tiempo de exposición al O2 continua a 0.5 vvm, 400 rpm de agitación y un control adecuado de temperatura, produce un vinagre de condiciones sensoriales aceptables.

Palabras clave: cacao CCN51, mucílago, acetificador, fermentación sumergida, cultivo "madre del vinagre”.

\section{Abstract}

This study development is based on the investigation about the feasibility to obtain a fermented product such as vinegar under a controlled pilot trial, which consist in design and developing a small scale acetator based on the Frings acetator, starting from the cocoa mucilage CCN51 wine, as a substrate, through a submerged fermentation and using as an inoculum the crop "vinegar mother" obtain vinegar according to the INEN 2296 norm requirements "vinegar requirements". Vinegar is obtained by two isolated microbial procedures, an alcoholic fermentation of the natural sugars present in the mucilage of cocoa and an oxidative fermentation from the obtained alcohol. A chemical characterization of substrate was made, establishing optimum conditions for an acetic fermentation. A completely randomized design was experienced for the investigation considering the effect of exposure to the $\mathrm{O}_{2}$ in 3 levels $\left(\mathrm{T}_{1}=24, \mathrm{~T}_{2}=18, \mathrm{~T}_{3}=12\right.$ hours/day) from different aeration periods of time each level with two repetitions using as volume constant unit of oxygenation 0.5 vvm (air volume by unit medium volume per minute) analyzing the effect on the acid acetic production $(\mathrm{g} / \mathrm{L})$ and the final vinegar physicochemical and sensorial characteristics. The data were statically analyzed determining that the T1 was the best obtained reaching the highest acetic acid production $4.05 \mathrm{~g} / \mathrm{L}$ as result of a higher oxygen concentration dissolved in fermentation, meeting the INEN No. 2296 NORM specifications. The same treatment (T1) get also the higher score (3.94/5) according to the global acceptability in sensorial evaluation by attributes regarding to T2 and T3. It was concluded that the acetic fermentation given to the wine of mucilage cocoa $\mathrm{CCN}_{51}$ with a continuous exposure to $\mathrm{O}_{2}$ at $0.5 \mathrm{Vvm}, 400 \mathrm{rpm}$ agitation and adequate temperature control, produces acceptable sensory conditions vinegar.

Key words: cocoa $\mathrm{CCN}_{51}$, mucilage, acetator, submerged fermentation, inoculum "vinegar mother". 
Optimización y aprovechamiento del residuo (exudado del mucílago) de la almendra fresca del cacao (Theobroma cacao l.) CCN51 en la elaboración de vinagre

\section{Introducción}

Conociendo la viabilidad de obtener vinagre partiendo de un sustrato alcohólico por medio de la oxidación del etanol por acción de las bacterias acéticas, se investigó la viabilidad de obtener vinagre utilizando el vino del exudado del mucílago del cacao obtenido de la fermentación alcohólica óptima del exudado del mucílago de cacao investigado por Luzuriaga, D. (2012). Partiendo del prensado de la almendra mucilaginosa y captando el mucílago residual resultante de la fermentación espontánea de la almendra de cacao, el cual comúnmente se genera en gran cantidad durante el proceso de extracción de la almendra fresca en el lugar (Kalvatchev, Garzaro \& Guerra, 1998). Considerando que actualmente existen dos métodos diferenciados para la producción de vinagres de vino: el método tradicional (lento) y los métodos rápidos (Tsefaye et al., 2002).

Se optó por utilizar como inóculo al cultivo llamado "madre del vinagre" (cultivo superficial) en una fermentación por cultivo sumergido, realizado en un acetificador Frings piloto diseñado para la investigación. Buscándose aprovechar este líquido reduciendo el impacto ambiental y contribuyendo a la productividad de la industria cacaotera como un valor agregado de la misma.

Económicamente se aprovecha sólo la almendra que representa un $10 \%$ de la masa del fruto fresco cosechado, esto ha derivado en serios problemas ambientales debido a que la pulpa y cáscara se desechan en terrenos aledaños a los cacaoteros, lo que deriva a su vez en la contaminación de suelos y cuerpos de agua cercanos en época de lluvias así como olores fétidos y deterioro del paisaje (Franco et al., 2010).

La variedad de cacao ecuatoriano CCN51 (Colección Castro Naranjal, cruce 51) es una de las fortalezas agronómicas del país, se ha probado que con la utilización de prácticas adecuadas puede ser un cultivo resistente a plagas y enfermedades alcanzando altos niveles de productividad (Rojas, 2007).
El objetivo de la presente investigación fue demostrar la viabilidad del aprovechamiento del exudado de mucílago del cacao CCN51en la elaboración de vinagre.

\section{Materiales y Métodos}

Las mazorcas de cacao variedad $\mathrm{CCN}_{51}$ (clon del cacao Nacional), fueron recolectadas de forma manual en la provincia de Los Ríos, cantón Montalvo, parroquia Sabaneta, recinto Pretoria en Ecuador; escogiendo los frutos maduros, tomando en cuenta parámetros como: madurez (color amarillo-rojizo) y apariencia física (libre de enfermedad y sin golpes).

\section{Proceso de Elaboración del Vino de Cacao}

Se elaboraron 6 mostos a partir del exudado del mucílago de cacao, se realizó de acuerdo al proceso óptimo según Luzuriaga (2012). Ésta fermentación se obtuvo mediante levaduras saccharomyces cerevisiae, con la corrección previa de grados Brix (con adición de sacarosa) y adición de metabisulfito de sodio. Para la fermentación, se utilizaron dos matraces Erlenmeyer con capacidad para 2,5 L cada uno, tapados herméticamente y con una trampa de agua mediante el uso de un tubo pírex, el cual permitió la salida del dióxido de carbono producido en la fermentación e impidió el ingreso de oxígeno. También se implementó una boquilla de salida y entrada en la parte inferior de los matraces (para uso posterior en el desarrollo de la fermentación acética) para la toma de muestras, análisis de las mismas ( ${ }^{\circ}$ Brix, $\left.\mathrm{pH}\right)$ así como facilitar el trasiego del vino para su embotellado, sin los sedimentos formados durante la fermentación (Figura 1). 


\section{b. Tapón de caucho}

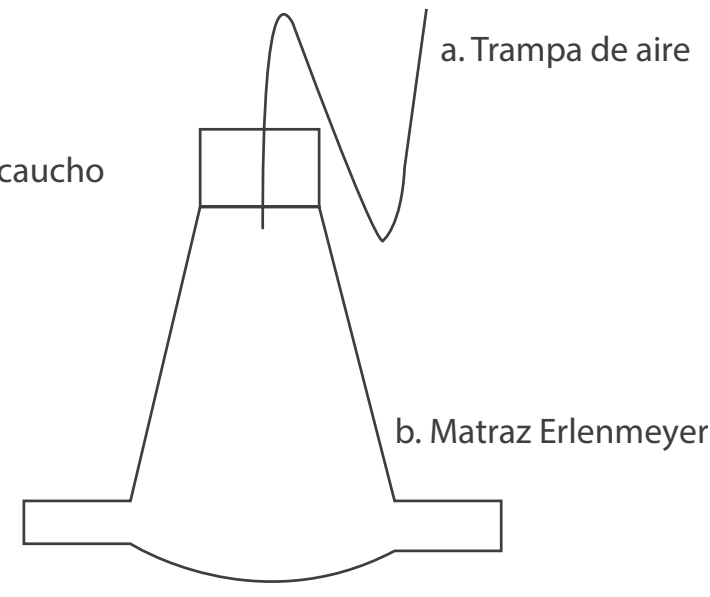

Figura 1. Esquema del micro fermentador utilizado para la fermentación alcohólica del exudado del mucílago del cacao.

\section{Obtención del Cultivo Madre del Vinagre}

Según Vegas (2010), en el año 1864, Luis Pasteur en Orleáns (Francia) explicó el proceso de elaboración de vinagres en barricas de madera por primera vez, de ahí toma el nombre de método Orleans o también conocido como Pasteur.

Se denomina método por cultivo superficial porque las bacterias acéticas (aerobios estrictos) se encuentran en la superficie del vino ya que oxidan el alcohol a ácido acético y forman una película de celulosa denominada "madre del vinagre". Está compuesto por bacterias acéticas y por levaduras, las cuales crecen simbióticamente. Las principales especies del genero Acetobacter productoras de ácido acético son Acetobacter aceti, xylinum y ascendes (Llaguno y Polo, 1991).

Se realizó un picado espontáneo en un vino blanco cepa Chardonnay Blanc marca "Doña Dominga", en un recipiente con amplia superficie de contacto con oxígeno tapado con gasas para evitar la contaminación física del cultivo. El método consistió en dejar en reposo el vino para que al cabo de aproximadamente cinco días, las bacterias del género Acetobacter creen una película de celulosa en la superficie, además del aumento en la acidez del vino, comprobándose la presencia de estas bacterias y utilizándose como cultivo "madre del vinagre" para la posterior fermentación acética del vino.

\section{Diseño Experimental}

Las condiciones óptimas de fermentación se refieren a la ventaja de conocer la información acerca de la cinética de crecimiento bacteriano y de los procesos automatizados de fermentación (Llaguno y Polo, 1991).

Se optó por reproducir condiciones óptimas de operación en el acetificador experimental; la temperatura en la cual el proceso de fermentación es viable, comprende un rango de $28-32{ }^{\circ} \mathrm{C}$ (Llaguno y Polo, 1991), el caudal de aireación se fijó en 0.5 vvm, ya que de acuerdo a De Ory citado por Pizarro (2005) debe ser aproximadamente de 50 $\mathrm{mL} / \mathrm{min}$ para $100 \mathrm{~mL}$ de medio (equivalente a $0.5 \mathrm{vvm}$ ), la agitación óptima usada fue de 400 rpm según Gómez et al., (1994).

Buscándose la aplicación del proceso en el lugar de la extracción del mucílago, partiendo de la probable operación del acetificador por parte de agricultores, se propuso variar el tiempo de exposición al oxígeno, buscando responder a una eventualidad en cuanto a la operación del mismo, siendo la incorporación de aire una variable esencial del proceso dado el carácter aerobio de las bacterias acéticas (Llaguno y Polo, 1991).

Para esto se empleó un diseño completamente al azar del efecto de un solo factor (tiempo de exposición al oxigeno) en 3 diferentes tratamientos de; 12,18 y 24 horas/día, así como 2 repeticiones de cada uno, lo que dio un total de seis unidades experimentales. Los resultados fueron procesados mediante un ANOVA simple utilizando el tiempo de exposición al oxígeno como variable independiente y como variable dependiente la acidez diaria producida. Las medias fueron comparadas con la prueba de diferencia mínima significativa (DMS) con un $\alpha=0.05$ (Tabla 1 ). 
Optimización y aprovechamiento del residuo (exudado del mucílago) de la almendra fresca del cacao (Theobroma cacao l.) CCN51 en la elaboración de vinagre

Tabla 1. Condiciones de agitación y oxigenación para cada tratamiento.

\begin{tabular}{|cccc|} 
TRATAMIENTO & $\begin{array}{c}\text { OXígenO } \\
\text { DISUELTO (h/día) }\end{array}$ & $\begin{array}{c}\text { AGITACIón } \\
(\mathbf{r p m})^{*}\end{array}$ & $\begin{array}{c}\text { VOLUMEN OXÍGENO } \\
\text { DISUELTO (vvm)** }\end{array}$ \\
\hline $\mathbf{1}$ & 24 & 400 & 0.5 \\
\hline $\mathbf{2}$ & 18 & 400 & 0.5 \\
\hline $\mathbf{3}$ & 12 & 400 & 0.5 \\
\hline
\end{tabular}

* Revoluciones por minuto

** Volumen de aire por unidad de volumen de medio por minuto.

\section{Acetificador Experimental}

Se utilizó el método de fermentación sumergida para realizar la investigación, debido a que industrialmente es el método con mejores rendimientos y más utilizado actualmente, el diseño del fermentador se basó en el acetificador Frings, el cual se adaptó a un modelo piloto, que constó de los siguientes componentes; matraz Erlenmeyer de 2,5 L. con dos boquillas (una para la toma de la muestra y otra para la entrada de oxígeno a la fermentación), agitador de vidrio impulsado por un motor paso a paso bipolar de rpm ajustable (construido para la investigación), bomba de aire con regulador de oxígeno disuelto en el medido en vvm, serpentín enfriador de vidrio adaptado al tapón de caucho con; tanque de alimentación, tanque de recepción y bomba de agua sumergible para permitir la recirculación del agua y termómetro (Figura 2).

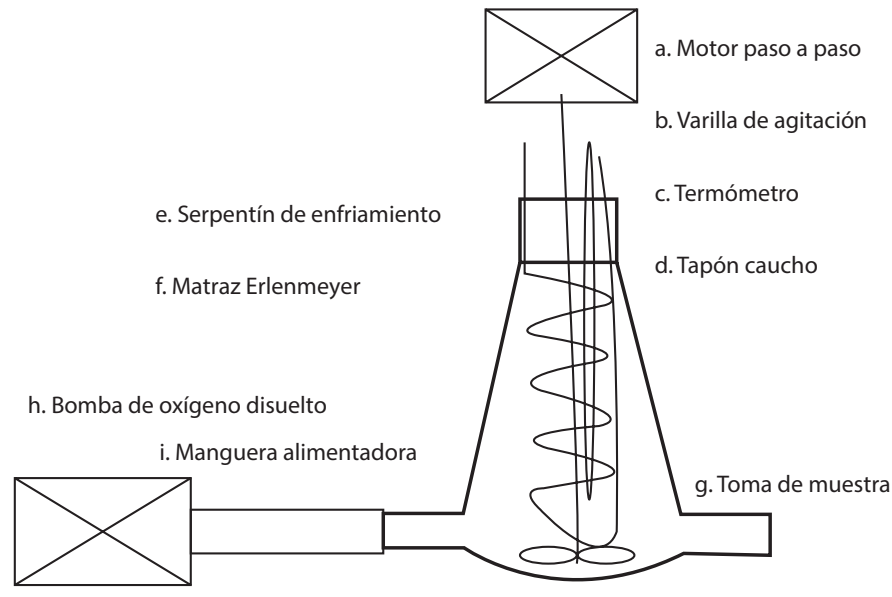

Figura 2. Esquema del acetificador experimental diseñado para el proceso de fermentación acética del vino del exudado del mucílago del cacao.

\section{Inoculación}

Se inocularon las dos primeras muestras del vino del mucílago del cacao con el cultivo madre obtenido, para posteriormente inocular consecutivamente los otros dos tratamientos, dejando un volumen aproximado del 15\% del volumen del matraz (327 mL), utilizado como cultivo madre para las posteriores repeticiones. Incrementándose así la acidez inicial de cada tratamiento.

\section{Adecuación}

Fue ajustada la bomba de oxígeno disuelto en el medio a través de un balance de masa conforme al volumen del medio, controlando temperatura de fermentación (semiautomáticamente) y ajustando las $400 \mathrm{rpm}$ del agitador por medio del motor paso a paso bipolar, así se dio inicio al proceso de fermentación acética.

\section{Pasteurización}

Se pasteurizó el vinagre obtenido, ya que a través de este tratamiento se destruyen las bacterias y se inactivan enzimas responsables de posibles alteraciones del vinagre final, evitando la sobre oxidación y producción de compuestos diferentes a los deseados.

\section{Análisis Sensorial}

Se realizó a 60 panelistas no entrenados que cumplieran con dos características específicas; consumidores habituales de vinagre y que hubiesen probado el fruto (cacao). Los atributos de aceptabilidad evaluados fueron:

- Apariencia

- Aroma

- Color

- Sabor

- Acidez

\section{Aceptabilidad general}

Las muestras fueron presentadas en vasos desechables rotulados de acuerdo al tratamiento, junto con un vaso de agua para enjuague entre muestra, evaluando el punto de "aceptabilidad general" utilizando lechuga (Lactuca serriola) como medio real de 
prueba. Utilizando una escala estructurada de 5 puntos de "Me gusta mucho" a "Me disgusta mucho" para los atributos. Los resultados fueron procesados completamente al azar mediante un ANOVA multifactorial de bloques, utilizando la prueba de diferencia mínima significativa (DMS) con un nivel de confianza del $95 \%$.

\section{Resultados y Discusión}

Extracción, caracteristicas y acondicionamiento del Líquido Exudado del Mucílago de Cacao

Se extrajo el exudado del mucílago de cacao por prensado, aplicando una relación 1:1 (peso del mucílago/peso de la prensa). El resultado del análisis fisicoquímico y proximal realizado al líquido exudado del mucílago de cacao se presenta en la Tabla 2. El total extraído $(13.08 \mathrm{~L})$ se repartió en 6 diferentes mostos acondicionados de 2,180 L (Tabla 3).

Tabla 2. Resultados del análisis Físico-Químico y Proximal del Exudado del Mucílago de Cacao.

\begin{tabular}{|cccc|}
\hline PROGRAMA DE EXAMEN & UNIDADES & RESULTADO & MÉTODO DE ENSAYO \\
\hline Sólidos Solubles ( ${ }^{\circ}$ Brix $)$ & $\%$ & 15 & REFRACTÓMETRO* \\
\hline Acidez Titulable & $\%$ & 1,0 & PEE-LASAFQ 16 \\
\hline pH & - & 3,59 & pH-metro* \\
\hline Proteína & $\%(\mathrm{f} 6,25)$ & 0,4 & PEE-LASAFQ-11 \\
\hline Humedad & $\%$ & 86,5 & PEE-LASAFQ-10a \\
\hline Grasa & $\%$ & 0,1 & PEE-LASAFQ-10b \\
\hline Cenizas & $\%$ & 0,3 & AOAC 923.03 \\
\hline Fibra & $\%$ & 0,1 & ICC STANDARD 113 \\
\hline Hidratos de Carbono & $\%$ & 12,6 & LASA BR01 \\
\hline Energía & $\mathrm{kcal} / 100 \mathrm{~g}$ & 52,9 & LASA BR02 \\
\hline SólidosTotales & $\%$ & 13,5 & AOAC 925.10 \\
\hline Azúcares Totales & $\%$ & 16,5 & AOAC 974.06 \\
\hline
\end{tabular}

(LASA, 2011).

Laboratorio de Análisis de Alimentos y Productos Procesados

*Desarrollado en la Planta Piloto de Alimentos UTE
Tabla 3. Parámetros iniciales del proceso de fermentación alcohólica.

\begin{tabular}{|ccc|}
\hline PARÁMETRO & CANTIDAD & DETALLE \\
\hline Saccharomyces cerevisiae & $0.15^{*}$ & $\mathrm{~g} / \mathrm{L}$ mosto \\
\hline pH mosto & $3.79 \pm 0.3$ & En los 6 mostos \\
\hline${ }^{\circ}$ Brix & 15 & En lo s 6 mosto s \\
\hline Metabisulfito de sodio & $0.16^{* *}$ & g/L mosto \\
\hline Temperatura de fermentación & 25.5 & ${ }^{\circ}$ C. Constante en los 6 mostos \\
\hline Azúcar & 52.53 & g. en 2, 18 L. de mosto $\left(17^{\circ} \mathrm{Bx}\right)$ \\
\hline
\end{tabular}

* Arozarena (2007) ** Ruiz (2011).

\section{Fermentación Alcohólica del Exudado del Mucílago de Cacao CCN51}

Las seis fermentaciones siguieron las mismas condiciones variando ligeramente características fisicoquímicas de la materia prima (líquido exudado del mucílago del cacao), como acidez inicial y pH; igualmente a los 10 días de fermentación se alcanzaron los mismos resultados, teniendo un consumo de sólidos solubles parecido (Figura 3). El análisis fisicoquímico del sustrato obtenido (vino) se presentan en la Tabla 4.

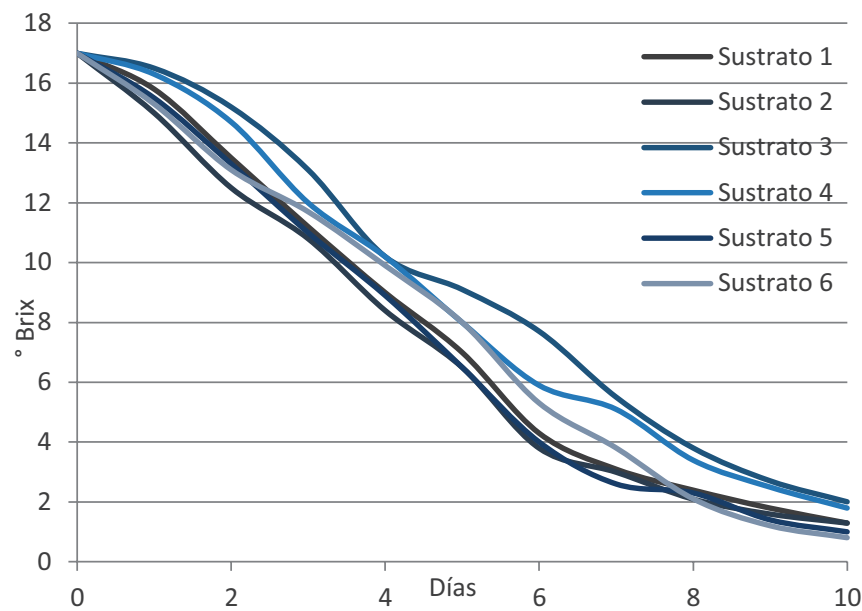

Figura 3. Cinética de fermentación alcohólica del líquido exudado del mucílago de cacao $C \mathrm{CN}_{51}$ para los 6 sustratos. 
Optimización y aprovechamiento del residuo (exudado del mucílago) de la almendra fresca del cacao (Theobroma cacao l.) CCN51 en la elaboración de vinagre

Tabla 4. Análisis Fisicoquímico del sustrato.

\begin{tabular}{|c|c|c|c|c|}
\hline & ARÁME & O ANA & & \\
\hline \multirow{5}{*}{ MUESTRA } & \multicolumn{2}{|c|}{$\begin{array}{c}\text { Grado Alcohólico } \\
\text { a } 15^{\circ} \mathrm{C}\left({ }^{\circ} \mathrm{GL}\right)\end{array}$} & \multicolumn{2}{|c|}{$\begin{array}{c}\text { Acidez Total } \\
\text { (ácido acético) } \\
\text { (g/L) }\end{array}$} \\
\hline & \multicolumn{2}{|c|}{$\begin{array}{c}\text { Requisito de la } \\
\text { norma INEN } 374\end{array}$} & \multirow{2}{*}{\multicolumn{2}{|c|}{$\begin{array}{c}\text { Requisito de la } \\
\text { norma INEN } \\
374\end{array}$}} \\
\hline & & MAX & & \\
\hline & \multirow{2}{*}{\multicolumn{2}{|c|}{5}} & MIN & MAX \\
\hline & & & - & 2 \\
\hline 1 & \multicolumn{2}{|c|}{7.1} & \multicolumn{2}{|c|}{1.44} \\
\hline
\end{tabular}

(LABOLAB, 2012)

* Desarrollado en la Planta Piloto de Alimentos UTE

Adecuación del Cultivo Madre del Vinagre para su Utilización como Cultivo Sumergido.

Después de utilizar el método de picado acético espontáneo para obtener el cultivo madre responsable de la acetificación del vino, al quinto día del vino en reposo, se generó una película en la superficie del vino así como el aumento en la acidez (Tabla 5).

Tabla 5. Acidez total medida en el cultivo madre del vinagre.

\begin{tabular}{|cc|}
\hline $\begin{array}{c}\text { INóculo } \\
\text { (Madre del vinagre) }\end{array}$ & $\begin{array}{c}\text { ACIDEZ } \\
(\mathrm{g} / \mathrm{L})\end{array}$ \\
\hline Día 1 & $1.6 \pm 0.082^{*}$ \\
\hline Día 2 & $1.7 \pm 0.064^{*}$ \\
\hline Día 3 & $1.9 \pm 0.046^{*}$ \\
\hline Día 4 & $2.1 \pm 0.032^{*}$ \\
\hline Día 5 & $2.2 \pm 0.014^{*}$ \\
\hline
\end{tabular}

\section{*Método de análisis INEN 341}

Este comportamiento es descrito más detalladamente en la investigación de Pizarro (2005), que obtuvo un resultado similar al de esta investigación, reportando del día o al 4 una fase exponencial de crecimiento en el recuento de UFC/mL de Gluconobacter spp., aumentando la acidez acética (\%p/v).
Adecuación del Vino del Mucílago de Cacao para la Fermentación Ácido Acética.

Considerando los análisis fisicoquímicos del vino del mucílago del cacao, se inoculó el sustrato (vino) con el cultivo madre del vinagre obtenido, adaptando las condiciones experimentales de disponibilidad de oxígeno requeridas por cada tratamiento para la fermentación acética, tomando el ${ }^{\circ} \mathrm{GL}$ del análisis fisicoquímico del sustrato y determinándose $\mathrm{pH}$ y acidez iniciales de cada tratamiento.

La determinación de $\mathrm{pH}$ para los diferentes sustratos se realizó en la planta piloto de la Universidad Tecnológica Equinoccial. Esta medición no se encuentra dentro del rango óptimo establecido 5.4-6.3 (De Ley et al., 1984); sin embargo, las bacterias ácido-lácticas que oxidan el etanol a ácido acético, pueden existir a valores bajos de pH (Hernández, 2003). La determinación de la acidez expresada como ácido acético fue realizada según el MÉTODO AOAC 930.35, se utilizó como reactivo hidróxido de sodio $(\mathrm{NaOH})$ al $0.5 \% \mathrm{~mol}$ y utilizando la fenolftaleína como indicador. Se realizó en el lugar donde la fermentación fue llevaba a cabo. Se determinó al inicio, durante la fermentación (diario) y al final de la misma. Para las primeras dos réplicas inoculadas se observó un ligero incremento de la acidez con respecto a la acidez inicial del sustrato, debido a la mezcla sustrato-inóculo y al dejar aproximadamente un 15\% del volumen al final de cada fermentación ( $327 \mathrm{~mL}$ que sirvió como inóculo para el siguiente tratamiento) se incrementó gradualmente la acidez en cada tratamiento, es por eso que la acidez inicial es mayor a la reportada en el análisis fisicoquímico del sustrato (Tabla 6).

Tabla 6. Acidez total medida de cada muestra a fermentar.

\begin{tabular}{|ccccc|}
\hline TRATAMIENTO & $\begin{array}{c}\text { RÉPLICA } \\
\text { (sustrato + inoculo) }\end{array}$ & $\begin{array}{c}\text { ACIDEZ TOTAL } \\
\text { INICIAL (g/L) }\end{array}$ & $\begin{array}{c}\mathrm{pH} \\
\text { Réplica 1 }\end{array}$ & $\begin{array}{c}{ }^{\circ} \mathrm{GL} \\
\text { ( } \mathrm{mL} / \mathrm{L})\end{array}$ \\
\hline $\mathbf{1}$ & Réplica 2 & 1.64 & 3.5 & 7.1 \\
\hline $\mathbf{2}$ & Réplica 1 & 1.74 & 3.2 & 7.1 \\
\hline $\mathbf{2}$ & Réplica 2 & 1.74 & 3.3 & 7.1 \\
\hline $\mathbf{3}$ & Réplica 1 & 1.88 & 3.5 & 7.1 \\
\hline $\mathbf{3}$ & Réplica 2 & 1.88 & 3.2 & 7.1 \\
\hline
\end{tabular}


Fermentación Ácido Acética Dada al Vino de Mucílago de Cacao CCCN51

En el decimocuarto día de fermentación la determinación de acidez para los 3 tratamientos fue casi nula ( $1=0.03 \mathrm{~g} / \mathrm{L}$ ) considerando el máximo de producción obtenido para T1 que fue 0.5 g/L día. La producción total de ácido acético determinada para cada tratamiento fue; $\mathrm{T}_{1}=3,50 \mathrm{~T} 2=3,35$ y $\mathrm{T} 3=2,72(\mathrm{~g} / \mathrm{L}$ ) (Figura 4). El proceso de fermentación acido acética concluyó debido al estancamiento en la producción de ácido acético; esto debido al agotamiento del etanol en el medio (provocado por una posible evaporación del alcohol relacionada con su volatilidad y potenciada por la agitación constante durante el proceso), por inactivación de las bacterias acéticas o por efecto de Acetobacter que sobre oxida el ácido acético a $\mathrm{CO}_{2}$ y $\mathrm{H}_{2} \mathrm{O}$.

Se observó una producción de ácido acético en el proceso para los 3 tratamientos (respaldada por el consumo de etanol y el número de oxidación contenidos en el análisis fisicoquímico final del vinagre) (Figura 4), esta producción diaria de ácido acético para T1 que fue de 0.26 g/L día, en relación a Pizarro (2005), que aislando Gluconobacter spp., bajo condiciones iniciales; $4 \%$ v/v de etanol, 0.5 vvm y 150 rpm, obtuvo 2.88 g/L día, puede deberse a; una disminución en la proporción 1:1 de carga vino:vinagre en cada tratamiento (debido a una limitación en la materia prima) ya que Tesfaye et al., (2002) indica que el rendimiento del proceso incrementa cuando la tasa de proporción de carga del sustrato es 1:1, o a una pobre concentración de biomasa en el inóculo o incluso una inhibición del mismo, ya que Macías et al., (1997), indica que la alimentación de etanol a elevadas (<\%5) concentraciones implica un bajo rendimiento del proceso, lo que propicia un efecto inhibitorio del etanol sobre la biomasa.

En cuanto al resultado de T2 y T3 es similar a lo propuesto por Llaguno y Polo (1993), que indica que en experimentos de laboratorios se observa un fenómeno de recuperación parcial, e incluso total de la actividad al reestablecer la aireación al cabo de tiempos no excesivamente largos.

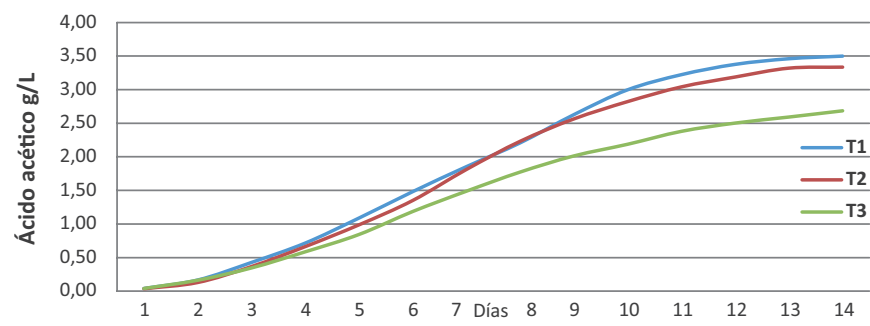

Figura 4. Cinética de Fermentación del Vinagre de Cacao $\mathrm{CCN}_{51}$ para cada tratamiento.

En la cinética de fermentación se observa una sección lineal en cierto momento y su gradiente (pendiente) es diferente para cada uno de los tratamientos. La Figura 5 se obtiene de datos promedios de las 2 réplicas de cada uno de los 3 tratamientos de ácido acético producido, esta etapa lineal de la curva de fermentación fue utilizada en los análsis estadísticos para determinar diferencias significativas entre tratamientos, en función de la producción de ácido acético por día (Tabla 6).

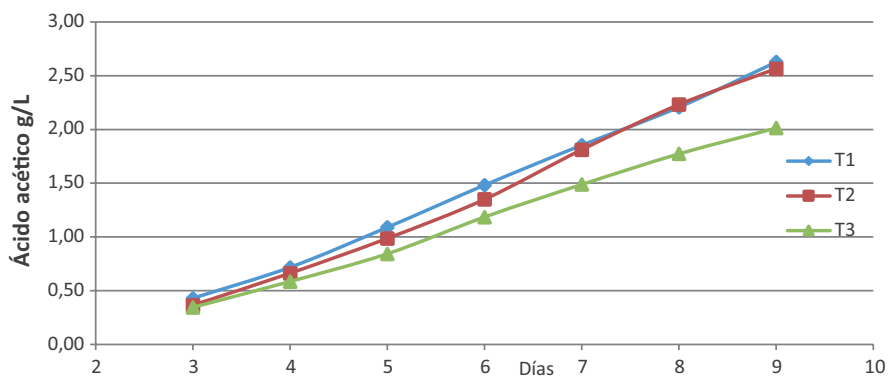

T1: $y=0.3694 x-0.7299 ; R^{2}=0.9985, T 2: y=0.3771 x-0.8389 ; R^{2}=0.9956, T 3: y=$ $0.2866 x-0.5436 ; R^{2}=0.9978$.

Figura 5. Producción de ácido acético en el proceso con respecto a los días del proceso.

Tabla 6. Gradiente de ácido acético producidos/día según tratamiento.

\begin{tabular}{|cc|}
\hline Tratamientos & Gradiente $^{\circ} \mathrm{Bx}$ \\
\hline T1 & $0.369 \pm 0.91^{\mathrm{a}}$ \\
\hline T2 & $0.377 \pm 0.70^{\mathrm{a}}$ \\
\hline T3 & $0.287 \pm 0.48^{\mathrm{b}}$ \\
\hline
\end{tabular}

DMS $x \pm \sigma(n=7)$

Letras distintas, indican diferencias estadísticas significativas $(p<0.05)$. 
Optimización y aprovechamiento del residuo (exudado del mucílago) de la almendra fresca del cacao (Theobroma cacao l.) CCN51 en la elaboración de vinagre

Al analizar la gradiente se observa un máximo de producción en la sección lineal para T1 no existiendo diferencia con T2; sin embargo, la producción de T3 se vio afectada por interrupción de oxígeno en el medio (Tabla 6).

Tabla 7. Resultado del Análisis Fisicoquímico del Vinagre del Vino de Cacao para los 3 Tratamientos.

\begin{tabular}{|c|c|c|c|c|c|c|c|c|}
\hline \multicolumn{9}{|c|}{ PARÁMETRO ANALIZADO } \\
\hline \multirow{4}{*}{ Tratamientos } & \multicolumn{2}{|c|}{$\begin{array}{l}\text { Alcohol etílico } \\
\text { a } 20^{\circ} \mathrm{C}\left({ }^{\circ} \mathrm{GL}\right)\end{array}$} & \multicolumn{2}{|c|}{$\begin{array}{c}\text { Acidez Total } \\
\text { (ácidoacético) }(\mathrm{g} / \mathrm{L})\end{array}$} & \multicolumn{2}{|c|}{$\begin{array}{l}\text { Número de } \\
\text { oxidación con } \\
\text { permanganato }\end{array}$} & \multicolumn{2}{|c|}{$\begin{array}{c}\text { pH } \\
\text { a } 20^{\circ} \mathrm{C}\end{array}$} \\
\hline & \multicolumn{2}{|c|}{$\begin{array}{l}\text { Requisito de la norma } \\
\text { INEN } 2296\end{array}$} & \multicolumn{2}{|c|}{$\begin{array}{l}\text { Requisito de la } \\
\text { norma INEN } 2296\end{array}$} & \multicolumn{2}{|c|}{$\begin{array}{c}\text { Requisito de la } \\
\text { norma INEN } 374\end{array}$} & \multicolumn{2}{|c|}{$\begin{array}{l}\text { Requisito de la } \\
\text { norma INEN } 2296\end{array}$} \\
\hline & MIN & MAX & MIN & MAX & MIN & MAX & MIN & MAX \\
\hline & - & 1,0 & 4 & 6 & 3 & - & 2.3 & 2.8 \\
\hline T3 & \multicolumn{2}{|c|}{0.00} & \multicolumn{2}{|c|}{4.00} & \multicolumn{2}{|c|}{17.75} & \multicolumn{2}{|c|}{2.7} \\
\hline T2 & \multicolumn{2}{|c|}{0.00} & \multicolumn{2}{|c|}{4.00} & \multicolumn{2}{|c|}{15.50} & \multicolumn{2}{|c|}{2.4} \\
\hline T1 & \multicolumn{2}{|c|}{0.00} & \multicolumn{2}{|c|}{4.05} & \multicolumn{2}{|c|}{19.10} & \multicolumn{2}{|c|}{2.6} \\
\hline
\end{tabular}

(LABOLAB, 2012), Laboratorio de Análisis de Alimentos y Productos Procesados

De acuerdo a la Tabla 7, el decremento del pH inicial en los 3 tratamientos, indica la oxidación del etanol.

La ausencia de grado alcohólico se debe a una pérdida del mismo en el proceso ya que es la acidez total del producto, dentro del rango permitido por la norma INEN 2296, por lo que se utilizó una muestra de cada tratamiento para analizar la aceptabilidad sensorial de cada uno.

El índice de oxidación determina que los compuestos volátiles que se encontraban en el mosto se oxidaron por lo que se evidencia la oxidación del alcohol volátil y otros compuestos en la fermentación.

\section{Análisis Sensorial del Vino de Cacao}

La Tabla 8 presenta las calificaciones por atributos del vinagre del cacao $\mathrm{CCN}_{51}$ de los tres tratamientos.
Tabla 8. Análisis Sensorial por Atributos del Vinagre de Cacao.

\begin{tabular}{|cccc|}
\hline ATRIBUTOS & T3 & T2 & T1 \\
\hline Apariencia & $3.32 \pm 1.0^{\mathrm{b}}$ & $3.78 \pm 0.9^{\mathrm{a}}$ & $3.62 \pm 1.1^{\mathrm{ab}}$ \\
\hline Color & $3.48 \pm 1.0^{\mathrm{a}}$ & $3.58 \pm 0.9^{\mathrm{a}}$ & $3.50 \pm 1.1^{\mathrm{a}}$ \\
\hline Aroma & $3.14 \pm 1.3^{\mathrm{a}}$ & $3.02 \pm 1.1^{\mathrm{a}}$ & $2.96 \pm 1.4^{\mathrm{a}}$ \\
\hline Sabor & $2.86 \pm 1.4^{\mathrm{b}}$ & $3.28 \pm 1.2^{\mathrm{ab}}$ & $3.74 \pm 1.0^{\mathrm{a}}$ \\
\hline Acidez & $2.84 \pm 1.3^{\mathrm{a}}$ & $3.22 \pm 1.2^{\mathrm{a}}$ & $3.22 \pm 1.2^{\mathrm{a}}$ \\
\hline Aceptabilidad general & $2.98 \pm 1.4^{\mathrm{b}}$ & $3.5 \pm 1.2^{\mathrm{a}}$ & $3.94 \pm 0.9^{\mathrm{a}}$ \\
\hline
\end{tabular}

Se observa que T1 con 79\% de aceptación general (3.94/5.0), mayor puntaje alcanzado (3.74/5) en cuanto al sabor (directamente relacionado) y al no existir diferencias significativas en otros atributos respecto a los otros tratamientos (T2 y T3) fue el mejor puntuado con una calificación promedio de "me gusta poco" por parte de los panelistas de acuerdo a la escala planteada. Sin embargo, en cuanto al aroma, T2 y T3 presentaron mejores calificaciones que T1, debido a una menor perdida de compuestos volátiles en el proceso (falta de oxigenación) y concuerda con Castro et al. (2002) que supone que los vinagres podrían ser caracterizados y diferenciados por la cantidad y calidad en los análisis de sus componentes volátiles.

Los atributos evaluados se observan en la Figura 6 representados en un gráfico de araña.

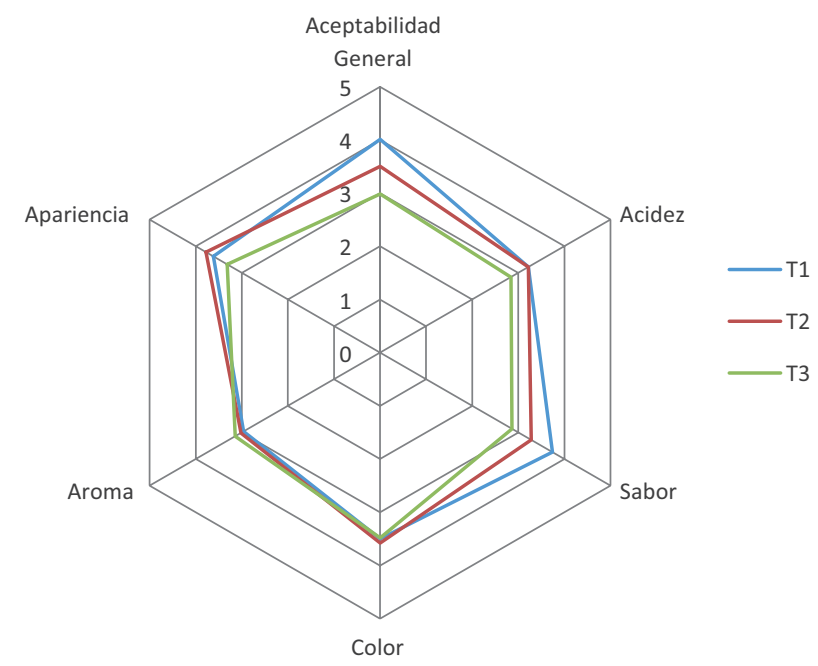

Figura 6. Análisis Sensorial por promedios de los Atributos del Vinagre del Vino del Cacao. 


\section{Conclusiones y Recomendaciones}

\section{Conclusiones}

Es posible la fermentación ácido acética del vino del mucílago del cacao CCN51, obteniendo un vinagre de acuerdo a la norma ecuatoriana INEN 2296 y de condiciones sensoriales aceptables.

La fermentación alcohólica dada al mucílago de cacao, permitió obtener un sustrato inicial óptimo para la acetificación del mismo.

Se obtuvo el inóculo madre por efecto de un picado espontáneo del vino, obteniendo microorganismos de la familia Acetobactereace sin identificar.

Existió una oxidación del etanol presente en el medio por parte de bacterias del género acetobacter debido al agotamiento del alcohol y a la producción de ácido acético en los 3 tratamientos, siendo el óptimo obtenido el T1 (exposición continua al oxígeno).

Las variables utilizadas en la investigación (400 rpm y 0.5 vvm) proporcionaron un bajo rendimiento de proceso.

La doble fermentación del exudado del mucílago (tanto alcohólica como acética) es posible en el lugar de su extracción, ya que el rango óptimo de temperatura de los procesos va de 25 a $32\left({ }^{\circ} \mathrm{C}\right)$ siendo similar a la del lugar del cultivo del fruto y posible extracción de la materia prima.

De acuerdo a la evaluación sensorial, T1 fue el de mayor aceptación general con un promedio cercano al 79\% o "me gusta poco" calificado por los panelistas. Destacando una baja puntuación en cuanto al atributo aroma debido a la pérdida de compuestos volátiles por demasiado tiempo de proceso.

\section{Recomendaciones}

Disminuyendo el tamaño de las partículas de oxígeno que ingresan al acetificador, se mejorará la superficie de contacto del oxígeno disuelto en el medio con las bacterias, obteniendo una mayor velocidad de acetificación.

Mejorando la capacidad, diseño y automatización del acetificador piloto planteado en la investigación, se disminuirá el tiempo de proceso, se mejorará la calidad y rendimiento del producto final y se potenciarán sus características organolépticas.

Se puede mejorar el rendimiento y velocidad de fermentación en el acetificador piloto planteado, aislando y utilizando modelos de cinética de crecimiento de acetobacter o realizando un estudio ecológico para determinar las cepas de acetobacter en la fermentación y así, adaptar las condiciones y nutrientes específicos para cada una.

\section{Referencias Bibliográficas}

Biotrade.(2010). Diagnóstico del Cacao Sabor Arriba, Programa Nacional de Biocomercio Sostenible - Ecuador. Recuperado el 6 de Enero del 2012, http://www.biotrade.org/ResourcesNewsAssess/ Diagnostico_Cacao_Arriba_Ecuador.pdf

Burbano, M. (2011). Ecuador de exportador del mejor cacao del mundo a exportador del mejor chocolate del mundo. Tesis de grado, Facultad Latinoamericana de Ciencias Sociales, Quito, Ecuador.

Castro, M., Natera R., García, M. \& García, F. (2002). Optimization of headspace solid-phase micro extraction analysis of aroma compounds in vinegar. J. of Chromatography.

Chiriboga, M., Picciono, R. (1982). La Producción Campesina Cacaotera: Problemas y Perspectivas. Quito, Ecuador: CAAP / CECCA.

Cho, M., Wang, S. (1990). Practical Method for Estimating Oxygen Kinetic and Metabolic Parameters Biotechology. Progress. American Institute of Chemical Engineers. Vol. 6. Recuperado el 24 de Noviembre del 2011 de, http://onlinelibrary.wiley.com/ doi/10.1021/bpooo02a012/abstract 
Optimización y aprovechamiento del residuo (exudado del mucílago) de la almendra fresca del cacao (Theobroma cacao l.) CCN51 en la elaboración de vinagre

Cinta M., Álvarez S. \& Zaragozá J. (1998). Química industrial orgánica. Valencia, España.: UPV

De la Torre, L., Navarrete, H., Muriel, P., Macia, M. \& Balslev, H. (2008). Enciclopedia de las Plantas Útiles del Ecuador. Quito \& Aarahus: Hermario QCA de la Escuela de Ciencias Biológicas de la Pontifica Universidad Católica del Ecuador \& Herbario AAU del Departamento de Ciencias Biológicas de la Universidad de Aarhus.

De Ley, J., Gillis M. \& Swings J. (1984). Bergey's Manual of systematic Bacteorology. Vol. 1, Family VI Acetobactereaceae. Edition: Krieg N. R. y Holt J. C. Williams \& Willkins, Baltimore, E.U.A.

El Universo. (Martes 19 de julio del 2005). Economía: Cacao $\mathrm{CCN}_{51}$ se reconoce como de alta productividad. Recuperado el 23 de Noviembre de 2011. http:// Www.eluniverso.com/2005/07/19/0001/9/2D498EAC6 A2C48F5B794AFA40F1F83Eo.html

Enríquez, G., Paredes, A. (1989). El cultivo del cacao (3a reimpresión de la za ed.). San José, Costa Rica: EUNED, Universidad Estatal a Distancia.

FAO. (Abril, 2010). G36 Theobroma cacao L. Recuperado el (9 de noviembre del 2010), de http://www.fao.org/AG/aga/AGAP/ FRG/afris/es/Data/521.HTM. Federación Nacional de Cafeteros de Colombia. Cacao. El Cultivo del Cacao, 1, 3, 22-27.

Franco, M., Ramírez, M., García, R., Bernal, M., Espinosa, B., Solís, J., Duran, C., (2010). Revista Latinoamericana el Ambiente y las Ciencias (1 (2):45-66). Puebla, México. Recuperado el 13 de Marzo del 2012 de http://www.buap.mx/portal_pprd/work/sites/redica/ resources/LocalContent/98/2/REAPROVECHAMIENTO\%20 INTEGRAL\%20\%20Franco-Castillo.pdf

García, J. (2008). Maridaje, enología y cata de vinos. Antequera, Málaga: Innovación y Cualificación Ediciones, S.L.

Gepts, P. (2002) (UC Davis department of Plant Sciencs) Recuperado el 18 de abril de 2011, de The Crop of the Day. Cacao, Theobroma cacao. The Divine Food: http://www.plantsciences.ucdavis. edu/gepts/pb143/crop/cacao/cacao.htm
Gómez, M., Romero, L., Caro, I. \& Cantero, D. (1994). Información Tecnológica (Vol. 5, Nº 6). Cádiz, España. Centro de Información Tecnológica. La Serena, Chile. Recuperado el 10 de Noviembre del 2011 de, http://books.google.com.ec/books?id=okLE-BgfY eYC\&pg=PA57\&lpg=PA57\&dq=crecimiento+acetobact er+fer mentacion+sumergida\&source=bl\&ots=GHZBmVEZ8n\&sig=a cJkeg-pRTkx8X1pHnPiYDqNfp8\&hl= en\&sa=X\&ei=QHKHULb4 CJGk8gTm5oDAAw\# v=onepage\&q\&f=false.

Herman, G., Reinhold, M. \& Gil, M. (2008). Procesos de Cocina. Madrid, España. Ed. Española, Akal ciclos formativos.

Hernández, A. (2003). Microbiología industrial. San José, Costa Rica: Euned

INEN 2296. Vinagre. Requisitos. Segunda revisión. 2003-12.

Kalvatchev, Z., Garzaro, D. \& Guerra, F. (1998). THEOBROMA CACAO L.: Un nuevo enfoque para nutrición y salud. p. 24

Llaguno C., Polo C. (1991). El vinagre de vino. Consejo Superior de Investigaciones Científicas. Madrid, España.

Luzuriaga D., (2012). Extracción y aprovechamiento del mucílago de cacao (theobroma cacao L.) como materia prima en la elaboración de vino. Tesis de grado, Universidad Tecnológica Equinoccial, Quito, Ecuador.

Macías, M., Caro, I. \& Cantero, D. (1997). Optimun operating conditions in closed-system industrial acetifiers (semicontinuous operation): a study by computer simulation. Chemical Engineering Journal 65.

Memorias del primer congreso venezolano del cacao y su industria. (02/2000). Maracay, Venezuela. Fundaacitte Aragua. Recuperado el 15 de agosto del 2012, de http://es.scribd. com/doc/ 86984357/Memorias-1er-Congreso-Vzlno-de-CacaoFundacite-Aragua.

Parés, R., Juárez, A. (2002). Bioquímica de los microrganismos. Barcelona España.: Reverté S.A. 
Peña, P., (25 de Septiembre de 2003). Chocolate - Origen e historia. P. Peña, Productor, \& RevistaCiencias.com. Recuperado el 21 de Diciembre de 2011, de http://www.revistaciencias.com/ publicaciones/EpyuVFuEV AdDjzYqXB.php

Pizarro, O. (2005). Obtención de condiciones de elaboración de vinagre de arándanos (Vaccinium corymbosum) utilizando torta de prensa. Tesis de grado, Universidad Austral de Chile, Valdivia, Chile.

Raymond, E., Donald F. (1966). Enciclopedia de la Tecnología Química. México, D.F.: Uteha.

Suarez, J. Iñigo B., (2003). Microbiología Enológica. Fundamentos de Vinificación (3a ed.). Madrid, España: Artes Gráficas Cuesta.

Tesfaye, W., Morales, M., García-Parrilla, M. \& Troncoso, A. (2002). Wine vinegar: Technology, Authenticity and quality evaluation. Trends in Food Science and Technology 13.

Vegas, C., (2011). Aplicación de métodos moleculares para el estudio de las bacterias acéticas implicadas en la elaboración de vinagre de vino tradicional. Tarragona España.: Universidad Rovira y Virgili. Recuperado el 28 de Agosto del 2012 de http://www. tdx.cat/bitstream/handle/10803/32784/TESI.pdf;jsessionid= 25276BA43F8F6E2ABFC3E49A32968ADD.tdx2.sequence=1.

\section{Anexos}

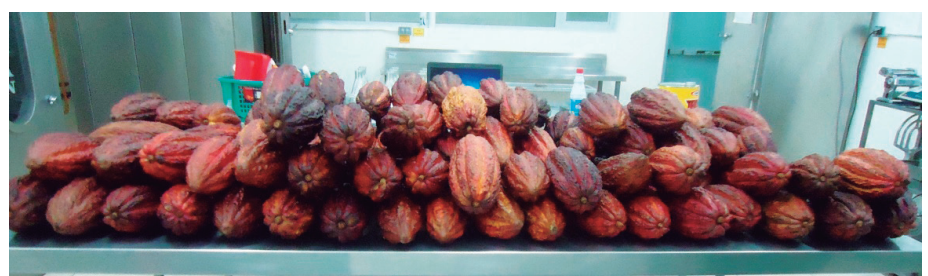

Mazorcas $\mathrm{CCN}_{51}$

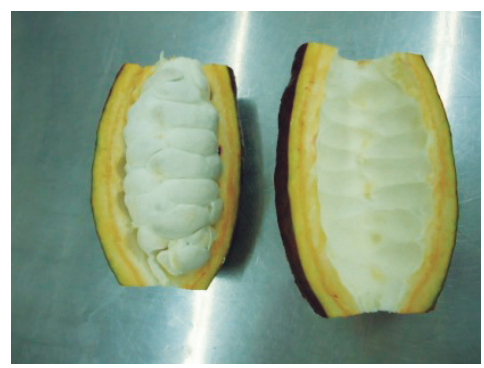

Mazorca corte (mucílago)

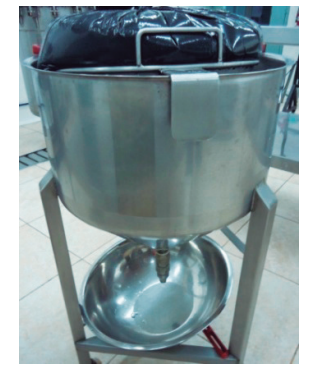

Extracción mucilago

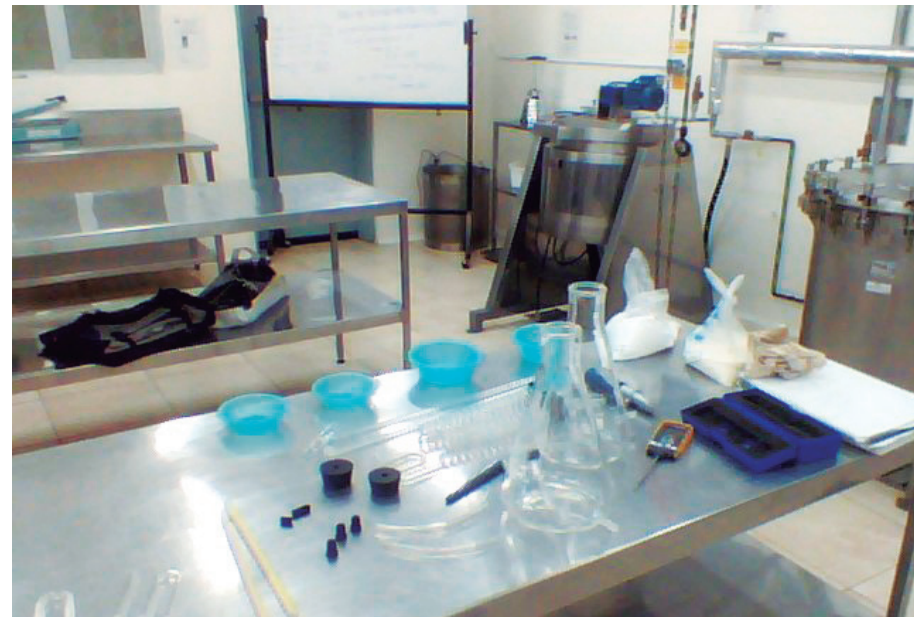

Materiales y equipos

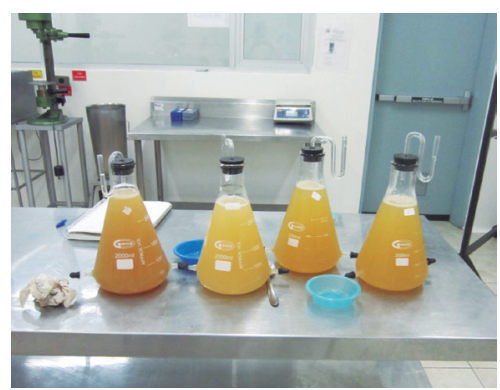

Vino del mucílago

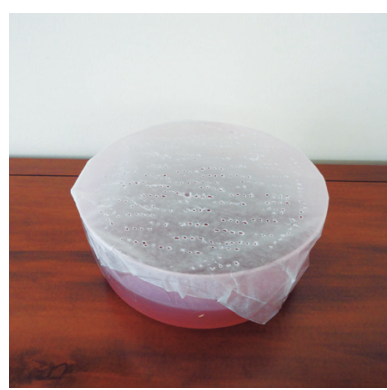

Cultivo madre del vinagre

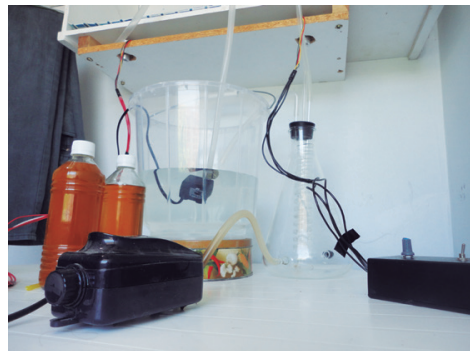

Acetificador piloto y vinagres

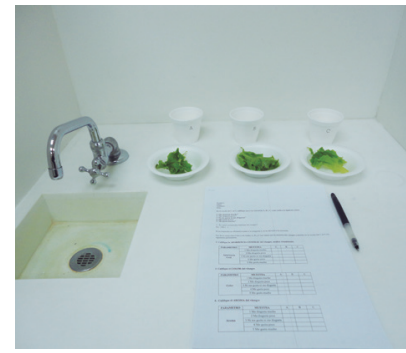

Análisis sensorial

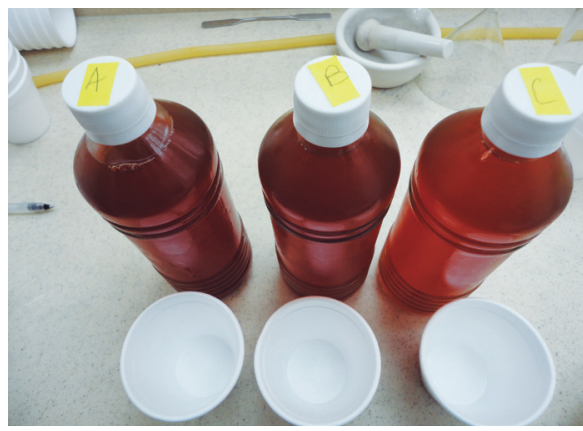

Vinagres 3 tratamientos

19

TsaFiquilus:ay 